\title{
Colônias de Povoamento versus Colônias de Exploração: de Heeren a Acemoglu*
}

\section{Settlement Colonies x Exploitation Colonies: from Heeren to Acemoglu}

\author{
Leonardo Monasterio** \\ Philipp Ehrl***
}

\begin{abstract}
Resumo: Este trabalho apresenta a evolução da tese de que o tipo de colonização inicial determina, ou condiciona, o futuro das sociedades. Smith (1776) já apresentava essa proposição e uma tipologia das colônias. Contudo, foram os autores alemães Heeren (1817) e Roscher (1856) os responsáveis pelo desenvolvimento da tese. Esses historiadores influenciaram o economista Leroy-Beaulieu (1902). E foi a partir desse economista francês que Caio Prado Júnior se baseou para aplicar a tese "colônia de povoamento versus colônia de exploração” ao caso brasileiro. Já nos Estados Unidos, a ideia ressurge nas obras de North $(1955,1959)$ e de Baldwin (1956). Mais recentemente, os historiadores econômicos Engerman e Sokoloff (1997) aprofundaram a questão, sem fazer referência aos autores europeus. Finalmente, Acemoglu, Johnson e Robinson $(2001,2002)$ levaram a tese para um público acadêmico mais amplo e apresentaram evidências econométricas. $\mathrm{O}$ trabalho conclui que o sucesso acadêmico da tese em questão decorre de sua flexibilidade. Os analistas favoráveis à economia de mercado podem atribuir o desenvolvimento econômico à qualidade institucional associada às colônias de povoamento. Já os mais críticos enfatizam o caráter espoliador das colônias de exploração.
\end{abstract}

Palavras-chave: Colonização. Colônia de povoamento. Colônia de exploração.

Abstract: The paper compares various forms of the thesis which states that the type of colonization determines or shapes the fate of societies. Smith (1776) already presented this proposition and a typology of colonies. Yet the German authors Heeren (1817) and Roscher (1856) were responsible for the elaboration of the thesis. These historians influenced the economist Leroy-Beaulieu (1902). And it was from this French economist that Caio Prado Júnior took the thesis "settlement colony versus exploitation colony" and applied it to the Brazilian history. In the United States, the idea reappears in the works of North $(1955,1959)$ and Baldwin (1956). More recently, economic historians Engerman and Sokoloff (1997) elaborated on the issue but without reference to European authors. Finally, Acemoglu,

* Somos gratos a Pedro Herculano de Souza, Claudio Shikida, Pedro Funari e Valdir Melo pelos úteis comentários e pelas correções. Leonardo Monasterio agradece o apoio da Capes (Processo BEX 2549/15-8).

* * Doutor em Desenvolvimento Econômico pela Universidade Federal do Paraná (UFPR). Professor do Programa de Pós-Graduação em Economia da Universidade Católica de Brasília (UCB). Pesquisador e técnico de Planejamento e Pesquisa da Diretoria de Estudos e Políticas Regionais, Urbanas e Ambientais (Dirur) do Instituto de Pesquisa Econômica Aplicada (Ipea). E-mail: leonardo.monasterio@gmail.com

*** Doutor em Economia pela Universität Passau (UP, Alemanha). Professor da Faculdade de Ciências Econômicas da Universidade Católica de Brasília (UCB). E-mail: philipp.ehrl@gmail.com 
Johnson, and Robinson $(2001,2002)$ spread the thesis to a wider academic audience and presented econometric evidences. The paper concludes that the academic success of the thesis stems from its flexibility. Market-friendly analysts can attribute economic development to the quality of institutions associated with settlement colonies, while the more critical ones emphasize the spoiling character of the colonies of exploitation.

Keywords: Immigration. Settlements. Extractive colonies.

JEL Classification: B00; N01.

\section{Introdução}

Aos 12 anos de idade, no sétimo ano do ensino fundamental, o estudante brasileiro típico é apresentado aos conceitos de colônia de povoamento e de exploração (SILVA NETO, 2012). Ele aprende que as primeiras se transformaram em países desenvolvidos, enquanto as demais, em subdesenvolvidos. Se esse mesmo estudante ler dois artigos publicados por Daron Acemoglu, Simon Johnson e James Robinson (2001, 2002), dos mais citados autores da área de Economia nos anos 2000, talvez se surpreenderá ao reencontrar, essencialmente, as mesmas proposições lá repetidas.

O objetivo deste trabalho é comparar as diversas formas dessa tese na obra de autores chave do pensamento econômico, buscando identificar as continuidades e descontinuidades na evolução dos conceitos de colônia de povoamento e de exploração. Mesmo concordando com esta tipologia e com aquela tese, há diferenças marcantes entre os autores no tocante aos mecanismos envolvidos, o papel das elites internas e externas e, mesmo, nos fatores de primeira ordem que levam à ocupação de uma área por um ou por outro tipo de colônia.

Devido à abrangência do tema, o escopo deste trabalho tem de ser modesto. Os autores aqui apresentados são muito influentes em suas próprias linhas teóricas. Logo, seria inviável examinar os estudos de seus seguidores ou os trabalhos empíricos. ${ }^{1}$ Nesse sentido, ficam de fora, por exemplo, estudiosos nacionais - como Furtado (1959) ou Novais (1986) -, que foram influenciados diretamente pela tipologia que Caio Prado Júnior reproduziu. Igualmente para manter o foco, são ignoradas as contribuições dos teóricos do imperialismo (HOBSON, 1902) e da dependência (CARDOSO; FALETTO, 1979) e de Wallerstein (2011).

Villela (2013) é - até onde se tem ciência - o primeiro a registrar a semelhança entre os conceitos em questão e as contribuições de Acemoglu, Johnson e Robinson. ${ }^{2} \mathrm{O}$ autor, contudo, remete à origem da dicotomia a Caio Prado Júnior

$1 \quad$ A literatura empírica que testa Acemoglu, Johnson e Robinson (2001, 2002) é imensa. Apenas para o caso brasileiro, pode-se citar Naritomi, Soares e Assunção (2012), Funari (2013), Carvalho Filho e Monasterio (2012), Menezes Filho et al. (2006) e Rocha, Ferraz e Soares (2017). Ver Albouy (2012) para uma crítica empírica àqueles autores.

2 Boianovsky (2009) é pioneiro ao apontar os paralelos entre a abordagem de Celso Furtado, Douglass North e autores recentes da Nova Economia Institucional. A relação entre esses dois primei- 
e não busca as influências do historiador brasileiro. Como se verá mais adiante, a obra de Arnold Hermann Ludwig Heeren (1817) foi a origem da tipologia que chegou aos livros escolares brasileiros.

Nosso estudo enfatiza dois pontos: a) a tese de que o tipo de colonização condiciona o futuro das sociedades foi formulada de forma independente mais de uma vez nos últimos séculos; e b) o sucesso da tese está relacionado com sua flexibilidade. Há uma linha condutora europeia clara formada por Heeren (1817), Roscher (1856) e Leroy-Beaulieu (1902). Em meados do século XX, a tese reaparece nas obras de North (1955) e Baldwin (1956). Já na virada do milênio, Engerman e Sokoloff (1997) desenvolvem a proposição e, por fim, Acemoglu, Johnson e Robinson (2001) a testam econometricamente. A prova da flexibilidade da tese é o próprio espectro ideológico e metodológico dos autores que a utilizaram. Ela foi aceita pelos membros da Escola Histórica Alemã, pelo ortodoxo - para sua época - Leroy-Beaulieu, por membros da New Economic History, como North, Engerman e Sokoloff, para chegar a Acemoglu, Johnson e Robinson. Conforme será visto adiante, a tese tanto pode servir à explicação do subdesenvolvimento como resultado da espoliação internacional, quanto também aos que atribuem o atraso econômico à falta de instituições pró-mercado.

\section{Os Precursores}

\subsection{Smith}

No capítulo "On colonies" ("As colônias"), de A riqueza das nações, Smith (1776) investiga a história da colonização e de sua função econômica e até acena com tipologia preliminar baseada na História Antiga. Smith escreveu o capítulo durante a Revolução Americana (1765-1783) e, portanto, sua preocupação volta-se para examinar o seu papel e as consequências econômicas dos "present disturbances" (SMITH, 1776, p. 186) para a economia inglesa. ${ }^{3}$ Ao fazer o balanço dos benefícios das colônias para a Europa, aponta o aumento da diversidade de bens e a expansão do mercado (SMITH, 1776, p. 223). Por sua vez, as distorções causadas pelas restrições ao livre comércio e os custos de proteção e manutenção das colônias as tornariam, no cômputo geral, um fardo econômico para os países europeus (SMITH, 1776, p. 225).

ros autores, incluindo o encontro de ambos na Sudene em 1961, foi retomada por Boianovsky (2018) e Boianovsky e Monasterio (2018). Fernandes (2011) reinterpreta as análises de Raymundo Faoro, Sérgio Buarque de Holanda e Celso Furtado a partir de Acemoglu, Johnson e Robinson (2002). Contudo, Caio Prado Júnior só é referido brevemente.

3 A riqueza das nações foi publicada em março de 1776, quatro meses antes da independência dos Estados Unidos. 
Para os fins deste trabalho, o relevante é apresentar a oposição entre as colônias gregas e romanas. Smith lembra que a palavra latina colonia significava simplesmente plantation, enquanto a palavra grega apoixia remeteria a "[...] separation of dwelling, a departure from home, a going out of the house [...]” (SMITH, 1776, p. 209). Ele afirma que nas colônias gregas:

A cidade-mãe, embora considerando a colônia como uma criança, sempre merecedora de grandes favores e ajuda e, em troca, devedora de muita gratidão e respeito, a tinha na conta de uma filha emancipada, sobre a qual não pretendia absolutamente exercer nenhuma autoridade ou jurisdição diretas ${ }^{4}$ (SMITH, 1776, p. 209, tradução nossa).

Já nas colônias romanas, não havia qualquer interesse de ter um Estado independente. Foram criadas como uma forma de que os ricos de Roma tivessem acesso a novas terras. Mesmo tendo alguma autonomia legal, deveriam ser vistas como um tipo de corporation, submetidas à autoridade da cidade-mãe.

Ainda sobre as colônias romanas, ele sustenta que se localizaram em áreas já povoadas, cabendo poucas terras para novos colonos e sem liberdade para cuidar de seus próprios interesses (SMITH, 1776, p. 213). Com isso, o desenvolvimento econômico teria sido mais limitado. Além disso, essas colônias seriam fontes de receitas para a sede do império, enquanto isso não aconteceria com as colônias gregas.

Voltando-se para as colônias de sua época, Smith (1776) afirma que superaram em muito as da antiga Grécia. Apesar de, inicialmente, se assemelharem com as romanas, a distância em relação à metrópole as teria tornado mais independentes, em busca de seus próprios interesses. A colônia de uma nação civilizada em uma terra vazia ou esparsamente povoada desenvolver-se-ia com mais velocidade que qualquer outra. A razão seria que os colonos trariam não só maior tecnologia, como também as instituições europeias. ${ }^{5}$

$4 \quad$ No original: "The mother city, though she considered the colony as a child, at all times entitled to great favour and assistance, and owing in return much gratitude and respect, yet considered it as an emancipate child, over whom she pretended to claim no direct authority or jurisdiction." (SMITH, 1776, p. 209).

$5 \quad$ Nas palavras de Smith (1776, p. 212): “The colonies carry out with them a knowledge of agriculture of other useful arts, superior to what can group up of its own accord in the course of many centuries among savage and barbarous nations. They carry out with them, too, the habit of subordination, some notion of the regular government which takes place in their own country, of the system of laws which support it, and of a regular administration of justice; and they naturally establish something of the same kind in the new settlement." Em português, "As colônias levam consigo um conhecimento da agricultura e de outros ofícios úteis, superior àquele que pode desenvolver-se espontaneamente entre nações selvagens e bárbaras, no decurso de muitos séculos. Além disso, levam consigo o hábito da subordinação, alguma noção sobre governo regular existente em seu país de origem, sobre o sistema de leis que lhe dá sustentação e sobre uma administração regular da justiça e, naturalmente, implantam algo do mesmo tipo na nova colônia." (tradução nossa). 
Naquele momento, Smith (1776) fez a diferenciação entre as colônias espanholas e as demais. Aquelas, desde o início, teriam sido fonte de receitas para a coroa, enquanto estas foram, em boa parte, esquecidas. $\mathrm{O}$ autor prossegue: as colônias espanholas talvez não tenham se desenvolvido justamente pela maior atenção que receberam. ${ }^{6}$ A menor liberdade dos colonos espanhóis teria sido uma das causas do seu mais lento desenvolvimento.

Ao voltar seu foco para colônias inglesas na América do Norte, Smith aponta que, apesar de as terras serem inferiores às sul-americanas, “[...] as instituições políticas das colônias inglesas têm sido mais favoráveis ao desenvolvimento e ao cultivo dessa terra [...]" (SMITH, 1776, p. 215, tradução nossa). ${ }^{7}$ Primeiro, as regras de ocupação da terra teriam gerado distribuição mais equitativa, por evitar a apropriação das não cultivadas. Além disso, como a taxação do trabalho dos colonos ingleses era menor, haveria maiores incentivos para produzir e acumular (SMITH, 1776, p. 2213). Por fim, as colônias inglesas foram favorecidas também por não terem sido submetidas a restrições tão graves no comércio internacional quanto às demais nações do Novo Mundo (SMITH, 1776, p. 216-220). Em suma, as colônias inglesas teriam tido melhor desempenho que as das demais nações europeias por não serem tão não liberais quanto as demais.

Smith (1776) antecipa a literatura ao tratar do papel das instituições de mercado e do capital humano para as diferentes trajetórias das colônias. ${ }^{8}$ Apesar de o autor iniciar a análise com um esboço de tipologia das colônias, acaba a desenvolvendo com ênfase no caráter da ocupação dado pelas diferentes potências coloniais. Em alguns momentos (SMITH, 1776, p. 234), traça paralelos entre as colônias britânicas no Novo Mundo e as gregas da Antiguidade; e também o faz entre as colônias romanas e as de Portugal e Espanha (SMITH, 1776, p. 224). Ou seja, Smith dá início à ideia de tipologia colonial, mas não a aprofunda tanto quanto os autores que se seguiram.

6 Sobre o Brasil, Smith (1776, p. 213) tem interpretação curiosa. Segundo ele, antes de terem sido encontrados metais preciosos, durante o período de esquecimento, o país teria se transformado em uma "great and powerful colony".

7 No original: "[...] political institutions of the English colonies have been more favourable to the improvement and cultivations of this land [...]" (SMITH, 1776, p. 215).

8 O autor mostra-se premonitório ao referir-se ao futuro das lideranças políticas das colônias da América do Norte: "From shopkeepers, tradesmen, and attornies, they are become statesmen and legislators, and are employed in contriving a new form of government for an extensive empire, which, they flatter themselves, will become, and which, indeed, seems very likely to become, one of the greatest and most formidable that ever was in the world." (SMITH, 1776, p. 236). Em português: "De lojistas, comerciantes e advogados, transformaram-se em estadistas e legisladores, estando empenhados em conceber uma nova forma de governo para um grande império, o qual, gabam-se eles, se transformará - e parece ter muita probabilidade de transformar-se efetivamente - em um dos maiores e mais formidáveis que jamais existiu no mundo" (tradução nossa). 


\subsection{Heeren}

O historiador Arnold Herrmann Ludwing Heeren (1760-1842) é o ponto de partida para a tipologia das colônias. Ele a apresentou em seu livro Handbuch der geschichte des europäischen staatensystems und seiner kolonien (Manual sobre a história do sistema de países europeus e suas colônias) (HEEREN, 1817). ${ }^{9}$ Renomado por suas contribuições em História Antiga, ele justifica o estudo das colônias pela sua importância no comércio e na própria política interna da Europa. Heeren (1817, p. 35) apresenta sua tipologia já na análise do que chama de primeiro período da formação do sistema colonial (1492-1515). A classificação estaria baseada no objetivo da instalação das colônias e seria a seguinte:

a) colônia de povoamento (ackerbaukolonie): a tradução literal seria colônia de agricultores. Optou-se por alterar o termo para manter consistência com a tradução feita por Leroy-Beaulieu (1902). Nesse tipo de colônia, os colonos são agricultores europeus e proprietários de terra. Esse tipo tenderia a tornar-se uma nação independente;

b) colônia de exploração (pflanzungskolonien): ${ }^{10}$ o objetivo seria a exportação de produtos primários para os países europeus. Geralmente, o número de europeus seria baixo, não se tornariam cidadãos locais e o uso de mão de obra escrava seria frequente. Com isso, afirma Heeren (1817), esse tipo de colônia não tende a desenvolver-se como nação;

c) colônia de mineração (bergbaukolonien): o objetivo seria a extração de metais preciosos. Os colonos europeus com o tempo adotariam identidades locais. Ocupariam amplos territórios, mas não tenderiam a ser bem-sucedidas, porque a ênfase seria apenas nas atividades de mineração, e os demais empreendimentos econômicos seriam negligenciados. Mais adiante no livro, Heeren (1817) inclui as colônias espanholas na América nessa categoria;

d) colônia mercantil (handelskolonien): existiriam para comercializar produtos primários do interior da colônia, produtos de pesca ou artesanato das populações autóctones. Começam como entrepostos, mas, pelo uso da força e da astúcia, poderiam ocupar vastas áreas. Os europeus seriam proprietários de terra, contudo, em número pequeno, não chegariam a ter identidade local.

Heeren (1817) apresenta diversos pontos relevantes sobre os efeitos de longo prazo da colonização. Em primeiro lugar, deixa claro que, mesmo havendo diferentes objetivos em uma mesma colônia, haveria um objetivo primordial que

9 A primeira edição do livro é de 1806, mas usou-se aqui a quinta edição.

10 Novamente, a tradução mais direta teria o sentido de colônia de plantation. Optou-se por outra tradução. 
daria o caráter geral da colonização. Além disso, ele é crítico ao afirmar que a colonização teve de início consequências adversas para ambas as partes envolvidas e - referindo-se às Índias Ocidentais e Orientais - que diferenças iniciais de ocupação geram resultados distintos no longo prazo. Porém, ele também é visionário ao apontar que as colônias e os países europeus viriam a constituir sistema econômico mais amplo e com mais liberdade.

Ao tratar da América espanhola, Heeren levantou também pontos interessantes sobre o processo colonial. Afirma que - apesar de herdarem as leis do país de origem -, com o tempo, as leis foram se organizando com as características locais, ou, em suas palavras, com o "espírito nacional" (HEEREN, 1817, p. 35). Nessas colônias de mineração, as diferenças étnicas teriam distanciado os governantes europeus da população não branca de tal forma que um sistema de castas se formou, com as ocupações superiores reservadas aos imigrantes. Isso teria feito com que a massa do povo nessas colônias não chegasse a constituir uma só nação. Por somente se interessar no envio das riquezas minerais para a metrópole, a coroa espanhola teria restringido a migração para suas colônias. Esse ponto sobre a natureza desigual e extrativa de certo tipo de colônia reaparecerá nos autores que se seguem.

\subsection{Roscher}

Roscher (1817-1894) foi professor de história na Universidade de Göttingen, a mesma em que Heeren foi mestre. Ele era um autor afamado entre os economistas. Schumpeter (1954) o cita uma dezena de vezes em seu History of economic analysis, na qual o aponta como uma das origens da Escola Histórica Alemã de Economia. Carl Menger (1968) dedica sua obra maior, Gesammelte werke: grundsätze der volkswirtschaftslehre, a Roscher.

Em Kolonien, kolonialpolitik und auswanderung, Roscher (1856) disserta sobre sua tipologia colonial. Esse autor mantém a estrutura de quatro classes, inspirada em Heeren (1817), mas inclui a colônia de mineração na pflanzungskolonien. Em seu lugar, acrescenta as colônias de conquista. Como Roscher aprofunda a classificação, vale a pena apresentá-la integralmente:

a) colônias de conquista (eroberungskolonien): tratam-se de colônias centradas na exploração dos nativos. Os colonos imigram em pequenos grupos - por período limitado de tempo - e não almejam beneficiar-se da sua própria produção, mas sim da exploração das populações locais. Os sistemas político e econômico mudariam após a conquista, mas o perfil étnico da população seguiria o mesmo. Não se trata da incorporação de territórios, porque, para isso, seria necessário que uma parcela considerável da população dominante se mudasse para as novas áreas. Roscher (1856) afirma 
que tal tipo de colônia exigiria algum desenvolvimento inicial e seria inapropriado para áreas pouco povoadas ou cultivadas, porque nestas não haveria ganho na pilhagem, ou mesmo, em governar os nativos. Outro requisito é que a nação dominadora deveria ser muito mais desenvolvida em termos de poder ou de educação política. Roscher (1856) inclui na categoria de colônias de conquista desde a dominação dos cruzados na Palestina até as colônias normandas na Europa e as colônias espanholas no México, no Peru, no Chile e em outras regiões da América. Em apoio à sua classificação, ele lembra que os primeiros europeus nessas regiões eram chamados de "conquistadores". Nessas colônias de conquista, Roscher deixa claro o tom de exploração e aponta que as classes médias seriam divididas em castas para facilitar a dominação pelo povo colonizador. Nas sociedades em que isso já acontecia antes das chegadas dos europeus, o controle seria facilitado, pois bastava substituir o grupo dominante;

b) colônias de comércio (handelskolonien): seguindo a classificação de Heeren (1817), são os simples entrepostos comerciais instalados nas áreas em que haja produtos de interesse comercial, ou como ponto de apoio a rotas comerciais mais relevantes, ou para controlar o comércio internacional. Os enclaves portugueses na Ásia e na África entrariam nessa categoria. Roscher (1856) deixa claro que quase todas as colônias começam como de comércio. Com o passar do tempo, haveria três destinos possíveis: a chegada da colônia pode desestabilizar o território de destino fazendo com que o enclave seja ponto de partida para a formação de um novo império; já se a população local progredir, pode formar-se um movimento nacionalista ávido por participar do comércio internacional e que repelirá a intrusão dos estrangeiros em seu território; finalmente, o autor considera que a situação pode se manter no longo prazo - como na costa da África -, com entrepostos comerciais que alcançariam o interior do continente. As colônias de comércio se diferenciariam das de conquista, pois naquelas o controle do território e do povo local são bem menos intensos;

c) colônias de povoamento (ackerbaukolonien): são inicialmente pouco povoadas, com clima semelhante ao país de origem dos imigrantes. Segundo Roscher (1856), os cereais precisam do mesmo tipo de solo do que as florestas, logo esse tipo de colônia ocorreria em lugares que antanho foram ocupados por tal tipo de vegetação. Pela própria natureza e os períodos de cultivo, os colonos criam raízes familiares nas novas áreas. Com o tempo, a colônia transforma-se em um país independente, um desdobramento do país-mãe. Ainda de acordo com o autor, para formar uma colônia desse tipo, é necessário fluxo constante de imigrantes, sendo desejável que o país-mãe seja populoso. Para Roscher (1856), haveria tendência da bus- 
ca de climas semelhantes. Assim, os espanhóis teriam ido para o planalto mexicano, os alemães, para áreas montanhosas e os ingleses, para o norte da América. $\mathrm{O}$ autor aponta também que essas colônias tenderiam a ser mais "democráticas" - isto é, igualitárias. Os que para lá emigrariam, nem seriam os mais pobres sem recursos para a jornada, nem os ricos que não desejam as agruras da mudança. Ele afirma, ainda, que os ocupados nas tarefas rurais não têm tempo para servir um nobre ou, até mesmo, sustentar a igreja. Em suma, Roscher idealiza os agricultores como pessoas honestas envolvidas no trabalho, e não em atividades perfunctórias;

d) colônias de exploração (pflanzungskolonien): Roscher (1856) deixa claro que não são um subgrupo da colônia agrícola de povoamento. Tratam-se de sociedades que produzem produtos de alto valor comercial para as metrópoles e intensivas em trabalho. Ele afirma que os brancos não suportariam o clima das colônias e que, portanto, é necessário usar trabalhadores nativos ou trazer escravos. Apenas um pequeno grupo de colonos vem para o país de destino. Como escravos são um ativo caro, só os mais ricos para lá iriam e não se formaria uma classe trabalhadora propriamente dita. Os imigrantes não teriam quaisquer intenções de fincar raízes e voltariam para o país de origem, após terem acumulado riquezas. Isso faria também com que eles não tivessem interesse em montar escolas ou universidades. Segundo Roscher (1856), as ilhas do Caribe seriam a área típica das colônias de exploração. Igualmente, a faixa litorânea tropical e insalubre seria apropriada para esse tipo de ocupação. As ocupações espanholas do interior e das partes mais elevadas e menos quentes do continente americano, por sua vez, seriam incluídas na categoria de colônias agrícolas.

Por fim, Roscher (1856) explica que as colônias podem mudar de tipo ao longo de seu desenvolvimento. O Brasil, por exemplo, enquanto foi negligenciado pela metrópole, seria uma colônia de povoamento; depois se transformou em uma colônia de exploração. Já as Antilhas espanholas começam como colônia de conquista, passam para agrícola - após a eliminação dos nativos - e, finalmente, para colônia de exploração. Não há, portanto, para Roscher, path dependence que determine os destinos das novas áreas. ${ }^{11}$

11 Na verdade, ao finalizar sua tipologia, Roscher (1856) acrescenta, ainda, as curiosas kulturkolonien, quando o governo de um povo pouco educado convida a elite cultural de uma nação mais desenvolvida. Os soberanos russos, a partir de Ivan III, teriam tido tal prática. 


\subsection{Leroy-Beaulieu}

A Encyclopedia Britannica apresenta Pierre Paul Leroy-Beaulieu (1843-1916) da seguinte maneira: "[...] pode ser considerado como o principal representante na França da economia política ortodoxa, e o mais proeminente oponente do protecionismo e das doutrinas coletivistas [...]"12 (CHISHOLM, 1911, p. 485, tradução nossa).

Com produção intelectual diversa, Leroy-Beaulieu foi defensor da expansão colonial francesa e seu De la colonisation chez les peuples modernes (LEROY-BEAULIEU, 1902) sintetiza sua posição sobre o assunto. Boa parte do livro trata de recomendações para a correta administração colonial, mas também apresenta a tipologia assumidamente derivada da de Roscher (1856). Segue sua classificação (LEROY-BEAULIEU, 1902, p. 540-543):

a) os entrepostos ou as feitorias (comptoirs de commerce);

b) colônias agrícolas ou de povoamento (colonies agricoles ou de peuplement); e

c) colônias de exploração (colonies de plantation ou d'exploitation).

Como se vê, Leroy-Beaulieu (1902) exclui as colônias de conquista de Roscher (1856), mas mantém as demais categorias. As feitorias, países como Cingapura ou Hong-Kong, são equivalentes às colônias de comércio (handelskolonien) de Roscher. Ou seja, lugares localizados em rotas comerciais chave, em que um pequeno número de europeus controla uma área relativamente rica e povoada.

Já em relação às colônias de povoamento, Leroy-Beaulieu (1902, p. 541) descreve primeiro os requisitos para sua instalação:

a) as novas terras devem estar vazias ou pouco povoadas;

b) o clima da colônia deve ser semelhante ao da nação colonizadora; e

c) a metrópole colonial deve ser mais povoada, o suficiente a ponto de ser capaz de ter emigrantes sem se abalar.

Ele também destaca que não há necessidade de que a metrópole seja rica - ou que envie capitais -, pois o crescimento das colônias de povoamento é lento, mas será contínuo e sem limite. Mais igualitárias, essas colônias seriam sans exception de caráter democrático e, cedo ou tarde, se emancipariam do país que lhes deu origem. Leroy-Beaulieu (1902) cita a Nova Inglaterra e o Canadá como exemplos de colônia de povoamento.

Por fim, as colônias de exploração seriam aquelas criadas nas terras tropicais. Essas áreas exigiriam grandes capitais para serem ocupadas e o que ele chamou de "organização artificial do trabalho", como a escravidão, a servidão, o envio de pre-

12 No original: "[...] may be regarded as the leading representative in France of orthodox political economy, and the most pronounced opponent of protectionist and collectivist doctrines [...]" (CHISHOLM, 1911, p. 485). 
sos, ou o sistema de Wakefield (1833). ${ }^{13}$ A riqueza dessas colônias cresceria com tremenda rapidez, mas sujeita a crises. Além disso, a população é beneficiada de forma mais lenta e a situação social deixa a desejar. ${ }^{14}$ Além da maior desigualdade, Leroy-Beaulieu identifica também que as diferenciações sociais tendem a ser mais persistentes e a democracia mal recebida nas colônias de exploração.

\subsection{Caio Prado Júnior}

A influência de Leroy-Beaulieu (1902) na obra de Caio Prado Júnior (19071990) não deveria ser mistério. Afinal, o próprio autor cita Leroy-Beaulieu ao tratar da colonização em sua obra mais famosa (PRADO JÚNIOR, 1959). ${ }^{15}$ Contudo, são poucos os autores que destacam esse fato. Novais $(1969,1986)$ e, mais recentemente, Leonidio (1999) são as exceções por discutirem a leitura e a adequação da tipologia do economista francês à obra de Caio Prado Júnior. A maior parte da historiografia brasileira ignorou essa influência e assumiu que esse autor era o criador dos conceitos de colônia de povoamento e exploração.

De início, Prado Júnior (1959) mostra-se efetivo seguidor de Leroy-Beaulieu (1902), ao lembrar que - logo após o descobrimento - não haveria como instalar colônias de povoamento porque a Europa ainda não tinha se recuperado das perdas populacionais decorrentes da peste negra. No caso brasileiro, ele lembra que seria impossível que Portugal povoasse o território, dada sua pequena população. ${ }^{16}$

13 A Austrália, curiosamente, foi classificada por Leroy-Beaulieu (1902) como colônia de exploração pela sua vocação para a exportação de lã. Wakefield (1833) foi o influente defensor da instalação de colônias de povoamento britânicas na Oceania e no Canadá, mediante esquema que envolvia a fixação de preços artificialmente altos para o acesso à terra. Ele foi um dos precursores - como o próprio Domar (1970) afirma - da tese da incompatibilidade entre trabalho livre, abundância de terra e senhores de terra: "Onde a terra é muito barata e os homens são livres, onde qualquer um que quiser pode obter uma terra para si mesmo, não apenas o trabalho é caro, em relação à parcela do trabalhador no produto, mas a dificuldade é obter trabalho em qualquer preço." (WAKEFIELD, 1833, p. 247, tradução nossa). Leroy-Beaulieu considera que o esquema de Wakefield era uma forma de garantir artificialmente a mão de obra abundante para os capitalistes. Marx dedica um capítulo inteiro de O capital para criticar e ironizar o esquema de Wakefield (MARX, 2006, p. 383-392).

14 Nas palavaras de Leroy-Beaulieu (1902, p. 543): "L'état social de ces colonies [...] laisse toujours singulièrement à désirer; il n'y a pas d'égalités de conditions; l'absence des titres n'empêche pas la distinction des classes; il subsiste longtemps des différences d'origine qui ne s'effacent que bien lentment entre les divers rangs de la société. De telles colonies, em général, sont moins promptement mûres l'indépendance; l'esprit démocratique y est plus contesté." Em português: "A situação social dessas colônias [...] deixa sempre a desejar; não há igualdade de condições; a ausência de títulos [de nobreza] não impede a diferenciação de classes; permanecem por longo tempo diferenças de origem que desaparecem apenas lentamente entre os diversos escalões da sociedade. Essas colônias, em geral, são menos maduras para a independência; o espírito democrático é lá muito contestado." (tradução nossa).

15 Leroy-Beaulieu (1902) tinha amplo alcance para os intelectuais brasileiros da época. Gilberto Freyre também o cita em Casa-grande 8 senzala (FREYRE, 1933).

16 Nas palavras de Cameron (1993, p. 142), o império português era spread too thin. 
Prado Júnior (1959, p. 27-30) apresenta, então, sua leitura das categorias de colônias divulgadas por Leroy-Beaulieu (1902). Haveria aquelas zonas temperadas, como no norte da América, em que a ocupação teria se dado por motivos não relacionados ao projeto colonial. Em suas palavras, essas áreas receberam por dois séculos os "resíduos das lutas político-religiosas da Europa" e também os excedentes populacionais da Inglaterra. As colônias de povoamento, naquela época, seriam o resultado de circunstâncias especiais sem uma lógica econômica clara. Seriam sociedades semelhantes à sua origem, que se tornariam "pouco mais que simples prolongamento" do continente europeu (PRADO JÚNIOR, 1959, p. 27).

Nas áreas tropicais (as colônias de exploração), os europeus voluntariamente só iriam para comandar o trabalho de outros, quer nativos, quer escravos africanos (PRADO JÚNIOR, 1959, p. 27). Como colônia de exploração, tudo no Brasil seria montado com o intuito de fornecer produtos para o comércio. Em termos dramáticos, ele diz:

[...] se vamos à essência da nossa formação, veremos que na realidade nos constituímos para fornecer açúcar, tabaco e outros gêneros, mais tarde ouro e diamantes, depois, algodão e em seguida café para o comércio europeu. Nada mais do que isso. É com tal objetivo, objetivo exterior, voltado para fora do país e sem atenção às considerações que não fossem o interesse daquele comércio, que se organizarão a sociedade e economias brasileiras. Tudo se disporá naquele sentido: estrutura, bem como as atividades do país (PRADO JÚNIOR, 1959, p. 31-32).

Esse seria o sentido da evolução brasileira para Caio Prado Júnior. Como colônia de exploração, o mercado interno não importaria e tudo estaria voltado para o setor externo da economia, até mesmo após a independência. Para cumprir seu papel, instala-se no Brasil o trinômio: latifúndio, escravidão e monocultura. Isso limitaria decisivamente o desenvolvimento posterior da economia brasileira.

Caio Prado Júnior (1942, p. 30) identifica as diferentes trajetórias entre as colônias de povoamento e exploração. Enquanto uma é continuação do país de origem, outra seria uma sociedade nova, em que tudo estava montado para fornecer produtos para o comércio.

E o que determinaria a instalação de colônias de povoamento ou de exploração no Novo Mundo? Além da já citada disponibilidade de população, o clima, para Caio Prado Júnior (1942), condicionaria a escolha. Porém, ele relativiza a suposta impossibilidade de adaptação do europeu ao clima tropical. Ele afirma que há falta de predisposição, mas - talvez baseado na experiência brasileira - que isso poderia ser resolvido nas gerações subsequentes por um novo processo de adaptação. De um lado, ele reconhece que os trópicos foram barreira evidente ao 
homem branco, de outro, lembra que até mesmo nas zonas temperadas da Nova Inglaterra houve problemas de adaptação. ${ }^{17}$

Há dois pontos que valem a pena realçar: ao aplicar a tipologia em questão para o Brasil desde o descobrimento, Caio Prado Júnior a adapta para um momento histórico distinto do que Leroy-Beaulieu (1902) se referia. Este pensava seu esquema para o século XIX, e Caio Prado Júnior o aplicou para o antigo sistema colonial. Finalmente, é bastante interessante que este autor, sendo marxista, tenha baseado seu esquema na classificação de um ortodoxo como Leroy-Beaulieu e utilizado, inclusive, os mesmos termos.

\section{Teóricos do Desenvolvimento: North e Baldwin}

Com 35 anos, Douglass North publicou o artigo "Location theory and regional economic growth", no Journal of Political Economy (NORTH, 1955). Tornou-se um clássico da área de economia regional por questionar o consenso da época sobre as áreas novas. A posição hegemônica, de inspiração smithiana, afirmava que a primeira fase do desenvolvimento regional se dava a partir de economias de subsistência. Com seu crescimento, as atividades comerciais e de transportes surgiriam, bem como uma indústria incipiente ligada à atividade primária. Na continuidade do processo, a industrialização aconteceria. Por fim, a economia terceirizar-se-ia e a região passaria a ser exportadora de produtos, capitais e mão de obra.

North (1955) afirma que essas etapas não refletem a experiência histórica. Os Estados Unidos teriam sido ocupados como empreendimento capitalista, voltado não para a subsistência, mas para o mercado externo. As exportações seriam, assim, o fator motivador de ocupação e responsável pela instalação dos sistemas comerciais, bancários e de transporte. $\mathrm{O}$ autor argumenta também que o sucesso da base exportadora regional seria reforçado por melhorias na estrutura urbana, treinamento de mão de obra e acumulação de capital na região. Com as condições apropriadas, o mercado interno desenvolver-se-ia e esses sistemas seriam utilizados para a diversificação e, talvez, para a industrialização da região.

Em um artigo publicado quatro anos depois, North (1959) reconhece que seu paper anterior estava incompleto. A ampliação da base exportadora seria condição necessária, mas não suficiente para o crescimento regional. Tudo dependeria da função de produção do produto de exportação. O autor atribui a Robert Baldwin (1924-2011) a atenção para a importância da questão tecnológica envolvida na produção do bem exportado.

Baldwin (1956) constrói um exemplo bastante simplificado, com duas economias idênticas, mas com condições naturais distintas. Uma seria extensiva e a

17 Ver Mann (2013) para as dificuldades dos primeiros colonos na América do Norte. 
outra, não extensiva. Nas regiões propícias para a produção extensiva, haveria notáveis rendimentos crescentes no setor primário, o que torna ótima a produção em grandes propriedades, por exigir muitos trabalhadores e conhecimentos administrativo e técnico para sua gerência eficiente. Ainda de acordo com o autor, as economias cujo produto de exportação é extensivo são, desde o início, desiguais. Os muitos trabalhadores pobres e poucos qualificados, pelas próprias características da região, teriam sua mobilidade econômica restrita. Já os poucos e dispersos proprietários de terra da região reinvestiriam os lucros na mesma atividade. A carência de capacidade tecnológica e empresarial restringe o desenvolvimento empresarial. Enfim, a despeito de sua base exportadora crescer, a concentração de renda manter-se-ia, bem como o caráter exportador de produtos primários (BALDWIN, 1956, p. 358).

Como esperado, a situação seria oposta na produção não extensiva. A produção seria eficiente em escala familiar e a exigência de capital para o tamanho ótimo da unidade produtiva, pequena. A distribuição mais igualitária de renda geraria maior demanda por bens e serviços, que criaria oportunidades lucrativas nas atividades comerciais e industriais. Ainda de acordo com Baldwin (1956, p. 360), o resultado seria crescimento mais rápido e equilibrado na área não extensiva.

North (1959) adota a divisão de Baldwin (1956) entre sociedades com setores primários extensivos versus intensivos e aponta outras consequências. Ele afirma que nas sociedades desiguais (extensivas) os proprietários de terra não apoiariam gastos públicos em favor da educação, quando comparadas com as mais igualitárias. Nessa produção extensiva, North sustenta que a infraestrutura de transporte poderia levar ao desenvolvimento de poucos centros de coletas e exportação de bens, o que conduziria a, no máximo, uma indústria subsidiária ao produto exportado. No livro The economic growth of the United States 1790-1860 (NORTH, 1961), o autor aplica esse esquema analítico para analisar o desenvolvimento das regiões sul, oeste e noroeste dos Estados Unidos.

Assim, poder-se-ia dizer que, para North (1959) e Baldwin (1956), haveria outra loteria de commodities institucionais, para utilizar o termo de Díaz-Alejandro (1984) em outro contexto. ${ }^{18} \mathrm{O}$ sorteio estaria relacionado diretamente à função de produção do produto da base exportadora: se a produção for intensiva, o prêmio é uma sociedade igualitária e dinâmica; caso contrário, o triste destino é a desigualdade e o atraso econômico.

Não foi encontrada nenhuma referência em North (1955, 1956, 1959) e Baldwin (1956) aos autores já citados. ${ }^{19}$ Ao que parece, a tese foi desenvolvida inde-

18 O economista cubano chamou de "loteria de commodities" o fato dos destinos dos países da periferia dependerem de características geográficas do produto de exportação e da integração específica com a economia mundial.

19 Boianovsky (2009) aprofunda-se no tema das relações entre as abordagens de Celso Furtado e North. Ele suspeita que o pensador brasileiro leu North (1956) durante a estadia em Cambridge 
pendentemente pelos autores europeus do século XIX e os norte-americanos do XX. É interessante notar que North ainda não havia publicado seus trabalhos institucionais importantes, que o levaram a ganhar o prêmio Nobel em 1993. Mesmo assim, fica claro que ele já tinha intuição de que as condições iniciais de ocupação determinariam as instituições e o futuro das novas áreas. ${ }^{20}$

\section{Neoinstitucionalistas}

\subsection{Engerman e Sokoloff}

Stanley Engerman (1936-) e Kenneth Sokoloff (1952-2007) foram membros destacados da revolução cliométrica. Engerman publicou o clássico Time on the cross, com o ganhador do Prêmio Nobel Robert Fogel (FOGEL; ENGERMAN, 1974), o qual orientou Sokoloff no seu doutorado em Chicago. Engerman e Sokoloff (1997) escreveram Factor endowments, institutions, and differential paths of growth among: new world economies quando as explicações institucionais históricas para o desempenho das nações, como North $(1973,1990)$, já estavam consolidadas. Contudo, a maior parte dos trabalhos dos neoinstitucionalistas tenderia a comparar os desempenhos das ex-colônias de acordo com a potência colonial de origem.

Esse enfoque não consegue explicar as diferenças de performance entre países do Novo Mundo que compartilharam a mesma potência colonial. Engerman e Sokoloff (1997) buscam examinar, assim, os determinantes das próprias instituições e, com isso, voltam-se para o papel das dotações de fatores. Em relação à literatura anterior, os autores citam Baldwin (1956) como um dos que argumentou que tais dotações têm impacto de longo prazo. A inovação do paper seria, assim, o detalhamento de como as experiências díspares das colônias europeias - via instituições - impactaram o curso do desenvolvimento das sociedades.

Engerman e Sokoloff (1997, p. 272-274) apresentam três tipos de colônias:

a) colônias com climas e solos bons para a produção de culturas agrícolas de alto valor no mercado internacional: os ganhos de escala nas plantations e a mão de obra de cativos africanos conduziram a sociedade com distribuição desigual de riqueza e capital humano. Essa situação inicial gerou instituições "ruins", que perduraram até mesmo depois da abolição da escravidão. Nessa categoria, estariam os países produtores de açúcar, como Brasil, Cuba e as demais ilhas caribenhas;

no qual escreveu sua obra maior (FURTADO, 1959).

20 Aguilar Filho e Fonseca (2011) comparam os trabalhos posteriores de North, de caráter mais institucionalista, com o dos intérpretes do Brasil de inspiração weberiana (Sérgio Buarque de Holanda, Raymundo Faoro e Vianna Moog). 
b) colônias com grandes populações de nativos que sobreviveram ao contato com os europeus e onde instituições extrativas foram instaladas ou adaptadas: são as colônias espanholas em que a prática da encomienda levou à extração de recursos ou de tributos da população local. Mesmo sem economias de escala típicas do plantation, geraram-se sociedades tão desiguais quanto as do padrão anterior: instituições excludentes em que os nativos tiveram dificuldades de fugir dos pagamentos para as elites etnicamente distintas;

c) regiões com poucos nativos e condições naturais sem vantagens comparativas para produtos com economias de escala. Sem maior interesse das metrópoles colônias, com terra abundante e pouca necessidade de capital, estabeleceu-se sociedade com muitos proprietários livres. O caso típico seriam as regiões da América do Norte. ${ }^{21}$

Os dois primeiros tipos de colônias são inicialmente desiguais e com instituições extrativas voltadas à proteção das elites e à manutenção da desigualdade. Seriam, portanto, equivalentes às colônias de exploração. Já as do último tipo seriam as colônias de povoamento de Heeren (1817), Roscher (1856) e Leroy-Beaulieu (1902).

Engerman e Sokoloff (1997) consideram que as diferenças nas dotações de fatores entre as colônias acabam se tornando endógenas com o passar do tempo. Quando as colônias de exploração foram instaladas, as políticas mercantilistas de fato estavam voltadas a beneficiar as metrópoles. Até mesmo após a independência, os países preservaram suas instituições, quer pela própria dificuldade de alterá-las, quer porque as elites locais já haviam se entrincheirado.

No tocante à estrutura fundiária, Engerman e Sokoloff (1997) reconhecem que a função de produção é relevante, mas lembram que a concentração da propriedade da terra pode destoar da do tamanho das fazendas em operação. Arrendamento ou meação permitiriam que isso fosse possível. Mesmo assim, os dados sugerem que a estrutura inicial concentrada de posse conduziria a políticas de acesso à terra que perpetuariam a desigualdade (ENGERMAN; SOKOLOFF, 1997, p. 277). Em suma, a estrutura social das encomiendas gerou haciendas, que criaram instituições voltadas para as elites.

A política de imigração entre as colônias de povoamento e exploração também teria sido discrepante. De início, enquanto a Inglaterra apoiava a emigração de sua população para o Novo Mundo, a Espanha restringiu - com apoio dos que já tinha emigrado - os movimentos para suas colônias. No primeiro caso, uma população mais diversa teria cruzado o Atlântico; no segundo, foram os parentes

$21 \quad$ A Argentina poderia também ser incluída nessa classe, pois não possui terras apropriadas para o açúcar, mas sim para os grãos. A desigualdade manteve-se graças à criação de gado no pampa (ENGERMAN; SOKOLOFF, 1997). 
dos que já lá estavam. Só após a independência das colônias espanholas, essas restrições foram canceladas, mas, naquele momento, a atratividade dos países da América do Norte já era maior para os imigrantes europeus. ${ }^{22}$ Assim, nas colônias de exploração, quer aquelas com uso intensivo de mão de obra nativa, quer aquelas em que se recorreu ao escravo africano, as elites europeias conseguiriam distanciar-se e preservar seus privilégios. Para Engerman e Sokoloff (1997), nas colônias de povoamento, a política mais aberta de acesso à terra teria atraído grandes contingentes de trabalhadores. Isso ensejou instituições que promoveram a participação de maiores segmentos da população no mercado, o que - no longo prazo - garantiu o desenvolvimento dessas sociedades.

A endogeneidade da dotação de fatores no longo prazo é a principal contribuição de Engerman e Sokoloff (1997). De início, as características naturais indicam o produto a ser cultivado. Isso determina a escola ótima de produção, que, por sua vez, influencia a estrutura fundiária e a composição da mão de obra. Esses elementos ensejam as condições políticas que determinam as próprias instituições e as normas de acesso à terra, imigração e uso da mão de obra. Dessa forma, tem-se o mecanismo de path dependence institucional que gera as trajetórias divergentes das economias do Novo Mundo.

O momento decisivo para tal divergência entre as ex-colônias teria sido a industrialização. Segundo Engerman e Sokoloff (1997, p. 286-287), a maior igualdade nos Estados Unidos esteve associada à renda per capita maior, que criou um mercado para produtos industriais padronizados. Do lado da oferta, a maior igualdade - com ampla rede de pequenos negócios - teria promovido os desenvolvimentos físico e institucional do sistema financeiro e de transportes, bem como o desenvolvimento inovador que possibilitou a industrialização acelerada no século XIX na América do Norte. Enquanto isso, nas antigas colônias de exploração, tais mecanismos estiveram ausentes por muito mais tempo.

\subsection{Acemoglu, Johnson e Robinson}

O impacto de Acemoglu, Johnson e Robinson $(2001,2002)$ foi enorme. Não parece exagero afirmar que o artigo fez com que a história econômica se transformasse novamente em área atrativa para economistas acadêmicos. O criativo uso da econometria contemporânea - com estimação via variáveis instrumentais, para o tema do desenvolvimento no longo prazo - fez com que o paper fosse ensinado e inspirasse toda uma sequência de trabalhos publicados nas mais prestigiosas revistas. ${ }^{23}$ A reputação e as credenciais acadêmicas dos pesquisadores talvez tenham

22 Além disso, naquele momento, os imigrantes vindos da Europa não ibérica teriam já um capital humano maior que os que se dirigiram para a Ibero-América (ENGERMAN; SOKOLOFF, 1997, p. 279).

23 A busca no Google por arquivos formato pdf que contenham syllabus reversal of fortune acemoglu 
contribuído para o sucesso do artigo: Acemoglu (1967-) ganhou a medalha John Bates Clark e, hoje, é o sexto economista mais citado no mundo; Simon Johnson (1963-) era professor do Instituto de Tecnologia de Massachusetts (MIT); e Robinson (1960-), professor em Berkeley. ${ }^{24}$

Essencialmente, os artigos em questão são testes econométricos da tese colônia de povoamento versus exploração. Tal como os que os antecederam, Acemoglu, Johnson e Robinson (2001, p. 1.370) apontam que tipos diferentes de colonização geraram instituições que persistiram no longo prazo. De um lado, haveria os extractive states, cujo objetivo era transferir o máximo possível de recursos da colônia para a metrópole. Do outro, estariam aquelas colônias que reproduziam as instituições europeias, com garantias para a propriedade privada e os governos não extrativos (institutions of private property). Essa diferença inicial permaneceu no longo prazo e teria sido responsável pelas atuais diferenças de renda entre os países. ${ }^{25}$

Pela própria natureza e metodologia do trabalho de Acemoglu, Johnson e Robinson (2001), eles não detalham os mecanismos que teriam feito com que a reversão das instituições restringisse o crescimento econômico. De qualquer forma, concordam com Engerman e Sokoloff (1997, p. 286-287): a industrialização foi nevrálgica para as trajetórias dos dois tipos de sociedade. Como tratam dos países do globo onde conseguiram dados, o nível de análise é mais geral, sem atentar para os meandros do processo ou as idiossincrasias.

O esquema de causalidade é simplificado: parte-se da mortalidade potencial do colono para o desempenho atual; e o elo seriam as instituições. ${ }^{26} \mathrm{Um}$ ambiente natural com poucas ameaças à saúde dos colonos europeus tenderia a atrair colônias de povoamento. Já aquelas com ambiente mais refratário, medido pela mortalidade potencial do colono europeu, levaria à instalação de instituições extrativas. Ou seja, a chave seria muito mais as condições da colônia que os interesses ou as capacidades da metrópole.

Em Acemoglu, Johnson e Robinson (2002), o argumento é um pouco diferente do trabalho anterior dos autores. Além da questão da mortalidade, os autores destacam o papel da densidade populacional. Nas regiões mais densas - ou seja, relativamente mais ricas no século XVI -, os europeus tenderam a instalar instituições extrativas. Grandes populações possibilitavam a utilização de trabalho

gera 850 referências. Ambos os artigos contam com mais de dez mil citações no Google Scholar, segundo buscas feitas em fevereiro de 2015.

24 James Robinson hoje é professor em Harvard.

25 Os autores reconhecem que o argumento é relacionado com o de Engerman e Sokoloff (1997), mas, corretamente, apontam que estes teriam enfatizado a relação instituições-dotação de fatores-desigualdade (ACEMOGLU; JOHNSON; ROBINSON, 2001, p. 1373).

26 Os próprios autores admitem que as instituições são uma "caixa preta" nas suas teses (ACEMOGLU; JOHNSON; ROBINSON, 2001, p. 1395). 
cativo ou a taxação das populações nativas. ${ }^{27}$ Já nas áreas que eram pobres e pouco ocupadas, houve grande imigração europeia e reproduziram-se instituições pró-mercado, não extrativas.

Haveria, assim, a reversão institucional: os europeus teriam levado instituições que garantiam a propriedade privada nas regiões que eram pobres, enquanto, nas que eram ricas em 1500 , os recém-chegados introduziram ou preservaram as instituições extrativas. Mais uma vez, no longo prazo, a diferença institucional entre as áreas de colonização europeia (de povoamento) e as áreas com instituições extrativas (de exploração) teria sido responsável pela inversão das rendas per capita dos países colonizados pelos europeus entre 1500 e 2000.

\section{Uma Visão Geral}

\subsection{Quadro Comparativo}

No Quadro 1, tem-se uma visão comparativa das diferenças entre os autores sob escopo no tocante às colônias de exploração. Claro que são distintos em muitas outras dimensões. Foram selecionadas aquelas mais relevantes para o presente fim e simplificações foram necessárias. Optou-se por deixar de fora as visões de Smith (1776) e Heeren (1817). O autor escocês, conforme se viu, utilizou dicotomia distinta, baseada nas categorias da Antiguidade e - ao tratar das colônias de sua época - voltou-se para a questão das diferenças entre os países colonialistas. Seria imprudente resumir ou encaixar as considerações de Smith em um quadro comparativo. Já Heeren, apesar de ser sem dúvida influência decisiva na classificação de Roscher (1856), não ofereceu os elementos para preencher todas as células. Agregou-se, no caso de Roscher, as colônias de plantation - ou exploração, as pflanzungskolonien - às de conquista (eroberungskolonien), tal como fez Leroy-Beaulieu (1902), por motivos de síntese. Na questão dos determinantes da ocupação - desde Roscher (1856), ou até mesmo Heeren (1817) -, o clima surge como condicionante do tipo de colônia a ser criada. O primeiro, conforme se viu, tratou até da importância da salubridade para os europeus imigrantes. Nessa mesma questão, Roscher (1856), Leroy-Beaulieu (1902) e Prado Júnior (1942) lembram que, por vezes, as metrópoles coloniais não teriam tanta margem de manobra. Com pequena população, na prática, por exemplo, Portugal não poderia estabelecer uma colônia de povoamento no Brasil. Para o estabelecimento de colônias de povoamento, os demais atentam para a interação entre recursos naturais e as características tecnológicas dos produtos de exportação.

27 Acemoglu, Johnson e Robinson $(2001,2002)$ ressaltam que a pobreza relativa das colônias de exploração não decorre do envio direto de recursos para a metrópole. Com isso, eles se afastam das teorias que enfatizam a espoliação da periferia. 
Quadro 1 - Comparação das colônias de exploração

\begin{tabular}{|l|l|l|l|l|l|}
\hline \multicolumn{1}{|c|}{ Autor } & $\begin{array}{l}\text { Determinan- } \\
\text { tes do tipo } \\
\text { de colônia }\end{array}$ & $\begin{array}{l}\text { Impacto } \\
\text { inicial }\end{array}$ & $\begin{array}{l}\text { Impacto } \\
\text { posterior }\end{array}$ & $\begin{array}{l}\text { Espolia- } \\
\text { ção pela } \\
\text { elite in- } \\
\text { terna }\end{array}$ & $\begin{array}{l}\text { Explora- } \\
\text { ção pela } \\
\text { metrópole }\end{array}$ \\
\hline $\begin{array}{l}\text { Roscher } \\
\text { (1856), (erobe- } \\
\text { rungskolonien } \\
\text { e pflanzungs } \\
\text { kolonien) }\end{array}$ & $\begin{array}{l}\text { Geográficos } \\
\text { e popula- } \\
\text { cionais (da } \\
\text { metrópole). }\end{array}$ & $\begin{array}{l}\text { Desigual- } \\
\text { dade e } \\
\text { explora- } \\
\text { ção. }\end{array}$ & $\begin{array}{l}\text { Econômico; } \\
\text { institucio- } \\
\text { nal. }\end{array}$ & $\begin{array}{l}\text { Não } \\
\text { há elite } \\
\text { interna. }\end{array}$ & Sim. \\
\hline $\begin{array}{l}\text { Leroy-Beaulieu } \\
\text { (1902) }\end{array}$ & $\begin{array}{l}\text { Geográficos } \\
\text { e popula- } \\
\text { cionais (da } \\
\text { metrópole). }\end{array}$ & $\begin{array}{l}\text { Desigual- } \\
\text { dade. }\end{array}$ & $\begin{array}{l}\text { Econômico; } \\
\text { institucio- } \\
\text { nal. }\end{array}$ & Sim. & Não. \\
\hline $\begin{array}{l}\text { Prado Júnior } \\
\text { (1942) }\end{array}$ & $\begin{array}{l}\text { Climáticos, } \\
\text { políticos } \\
\text { e popula- } \\
\text { cionais (da } \\
\text { metrópole). }\end{array}$ & $\begin{array}{l}\text { Explora- } \\
\text { ção. }\end{array}$ & Econômico. & Sim. & Sim. \\
\hline $\begin{array}{l}\text { North (1959) e } \\
\text { Baldwin (1956) }\end{array}$ & $\begin{array}{l}\text { Tecnológicos. } \\
\text { Sesigual- } \\
\text { dade. }\end{array}$ & $\begin{array}{l}\text { Infraes- } \\
\text { econô- } \\
\text { mico; } \\
\text { capital } \\
\text { humano. }\end{array}$ & Não. & Não. \\
\hline $\begin{array}{l}\text { Engerman e } \\
\text { Sokoloff (1997) }\end{array}$ & $\begin{array}{l}\text { Dotação de } \\
\text { fotores; tecno- }\end{array}$ & $\begin{array}{l}\text { Desigual- } \\
\text { lade. }\end{array}$ & $\begin{array}{l}\text { Institucio- } \\
\text { nal. }\end{array}$ & Sim. & $\begin{array}{l}\text { Sim, antes } \\
\text { da inde- } \\
\text { pendência; } \\
\text { não. }\end{array}$ \\
\hline $\begin{array}{l}\text { Acemoglu, } \\
\text { Johnson e Ro- } \\
\text { binson (2001, } \\
\text { 2002) }\end{array}$ & $\begin{array}{l}\text { Climáticos; } \\
\text { mortalidade } \\
\text { dos europeus }\end{array}$ & $\begin{array}{l}\text { Institucio- } \\
\text { nal. }\end{array}$ & $\begin{array}{l}\text { Institucio- } \\
\text { nal. }\end{array}$ & Sim. & $\begin{array}{l}\text { Sim, antes } \\
\text { da inde- } \\
\text { pendência; } \\
\text { não. }\end{array}$ \\
\hline
\end{tabular}

Fonte: Elaboração própria.

A coluna dos mecanismos iniciais sintetiza qual seria o impacto inicial perverso da instalação das colônias de exploração. Em geral, o pecado original é a desigualdade. Apenas Prado Júnior (1942) diz que há problema em ter uma economia sem mercado interno, e Acemoglu, Johnson e Robinson (2001, 2002) afirmam que as instituições extrativas já são o entrave inicial.

Já no tocante ao mecanismo de manutenção do atraso, a diferença entre os autores é mais marcante. Para Roscher (1856), o problema é que nem se chega a ter uma elite nacional nas colônias. Como o interesse dos europeus é apenas explorar e retornar ao país de origem, não trazem efeitos benéficos para a sociedade 
colonial. Leroy-Beaulieu (1902), mesmo sem detalhar, faz referência a dois problemas das colônias de exploração: a maior tendência a crises e a falta de espírito democrático. Para Prado Júnior (1942), a carência de processo de acumulação interno e a espoliação estrangeira restringem o crescimento dessas colônias. North (1959) e Baldwin (1956) têm o mérito de apresentar os mecanismos econômicos de forma mais cuidadosa. Eles concordam que a maior desigualdade seria mantida via processos econômicos: a renda concentrada reduziria a demanda por bens localmente produzidos, além da falta de diversificação, de infraestrutura adequada e de capacidade empreendedora. North, como se viu, acrescenta que - na economia extensiva - os gastos em educação pública seriam menores e também a infraestrutura menos desenvolvida, o que prejudicaria o crescimento de longo prazo. Em seu turno, os autores contemporâneos recorrem a mecanismos institucionais para explicar como os efeitos das colônias de exploração se mantêm. Engerman e Sokoloff (1997) aprofundam a análise dos meandros desse processo ao perceberem que as instituições extrativas tornam endógena a própria dotação de fatores. Por fim, Acemoglu, Johnson e Robinson (2001, 2002) mantiveram um nível de análise mais geral sobre os mecanismos institucionais envolvidos e testaram econometricamente as conjecturas que seus antecessores não poderiam fazer.

Sobre a espoliação pela elite interna ou externa, também há ampla gama de visões. Para Roscher (1856), como não há propriamente elite interna, a exploração é externa. North (1959) e Baldwin (1956), por usa vez, tratam de regiões, e não países, e, portanto, é questionável diferenciar entre setor externo ou interno. De qualquer forma, a espoliação não é uma de suas preocupações. Os demais autores concordam que quer pelo uso de mão de obra cativa, quer pelas instituições extrativas, a elite local é beneficiada nas colônias de exploração. ${ }^{28}$

Os neoinstitucionalistas também admitem que o objetivo inicial das colônias desse tipo era basicamente o benefício das metrópoles. Após a independência dos países do Novo Mundo, as instituições extrativas já existentes passam a funcionar em favor das elites locais e não se faz referência à espoliação externa.

\subsection{A Trajetória da Dicotomia Colônia de Povoamento e Colônia de Exploração}

Quem criou a ideia de que o tipo de colonização importa para o futuro das sociedades? O fio que liga Heeren (1817), Roscher (1856), Leroy-Beaulieu (1902) e Prado Júnior (1942) é inquestionável. Já a linha de North e Baldwin até os autores recentes não é tão explícita. Engerman e Sokoloff (1997) citam Baldwin (1956) e, muito provavelmente - por estarem na mesma tradição -, foram influenciados por

28 Para Prado Júnior (1942), existe exploração interna, mas o peso maior está na espoliação externa pelos impérios coloniais. 
North (1959). Não há sinais, por sua vez, de que a tradição europeia e a norte-americana tenham se cruzado.

Seria a dicotomia colônia de povoamento e exploração, uma daquelas ideias - como o conceito de capital social (FARR, 2004) - descoberta e redescoberta a cada geração? Isso pode ser verdadeiro, afinal, trata-se de conjecturar a partir de realidade histórica que está à disposição de todos os pesquisadores. Eles observam o resultado do processo e atribuem as disparidades de desenvolvimento a um pecado original ocorrido no passado remoto. De acordo com essa visão, cedo ou tarde, pesquisadores independentes chegariam a conclusões semelhantes.

Pensando-se na evolução do pensamento econômico recente, também é algo previsível que os autores da linha norte-americana não tenham sido influenciados pelos europeus. Ao longo do século XX, o epicentro da pesquisa econômica afastou-se da Europa continental e foi na direção do Reino Unido e depois para os Estados Unidos. Esse triunfo da teoria econômica anglófona teve como efeito colateral o esquecimento de algumas contribuições relevantes de outros autores. ${ }^{29}$

É surpreendente que, hoje, a miríade de pesquisadores preocupados com a questão do desenvolvimento econômico citem apenas os autores mais recentes e ignorem as contribuições anteriores. Destacam Acemoglu, Johnson e Robinson $(2001,2002)$ e omitem seus antecedentes, mesmo os mais próximos. Fonseca (1996) refere-se à "falácia anacronística" na história do pensamento econômico - ou seja, a ideia de que os autores do passado seriam como primeiros rascunhos das teorias contemporâneas. Bastaria, assim, ler os autores atuais. Ao que parece, os pesquisadores coetâneos acreditam tanto em tal falácia que creem ser suficiente citar Acemoglu, Johnson e Robinson $(2001,2002)$ como os criadores da tese que relaciona a colonização e o destino das sociedades.

De qualquer forma, a tese "colonização importa" é bem-sucedida no mercado de ideias. Por quê? David Landes (1990) aponta que as explicações para a riqueza e a pobreza das nações podem ser reunidas em dois tipos. Uma diz que as ricas são trabalhadoras, bem-educadas, governadas e eficientes; a outra, que as ricas o são por terem explorado os inocentes, virtuosos e vulneráveis países pobres. Talvez o sucesso da tese colônias de exploração versus colônias de povoamento venha do fato de que pode - sem muita dificuldade - ser inserida em qualquer uma das narrativas citadas por Landes. Uns podem enfatizar que os países novos ricos tiveram sorte de terem como origem o tipo de colonização "correto" e, portanto, as instituições pró-crescimento. A ênfase nesse caso está nas regras pró-mercado e democráticas que lá se desenvolveram. Já outros podem lembrar que as colônias de exploração foram, afinal de contas, de exploração em benefício de

29 Um caso marcante foi o da tradição regional germânica do século XIX. As relevantes contribuições de Von Thünen (1826) passaram mais de cem anos praticamente esquecidas pelos economistas anglófonos. 
uma elite metropolitana e, depois, interna. Esses destacarão o aspecto da exploração de que foram vítimas os países hoje pobres.

Em outras palavras, a tese em questão é como espelho que reflete mais as crenças dos que o miram que um quadro definitivo, com conteúdo rígido. Em um extremo, os economistas pró-mercado consideram que o pecado original das ex-colônias de exploração é a falta de instituições de mercado. No outro, a marca indelével de ter sido explorado quando colônia é ser dependente e espoliado pelos países ricos.

\section{Considerações Finais}

Mostrou-se que a tese de que o tipo de colônia determina o futuro dos países foi abraçada por autores bastante díspares ao longo dos séculos. A proposição - com modificações - foi adotada por membros da Escola Histórica Alemã, ortodoxos liberais franceses, marxistas, cliometristas e estrelas acadêmicas contemporâneas.

Apesar de Smith (1776) ter apresentado a primeira dicotomia da colonização, apontou-se que a origem da tipologia deve ser atribuída ao historiador alemão Heeren (1817), no começo do século XIX. Este influenciou seu conterrâneo Roscher (1856) e o francês Leroy-Beaulieu (1902). No século XX, Prado Júnior (1942) baseou-se no último para buscar o sentido da história brasileira. Na década de 1950, surge o eixo norte-americano com os historiadores econômicos North (1959) e Baldwin (1956), que - mesmo sem apresentar evidências quantitativas - modernizaram a tese ao utilizarem conceitos da teoria econômica da época. Engerman e Sokoloff (1997) detalharam os meandros dos mecanismos que fariam com que as instituições das colônias de povoamento e as de exploração fossem distintas e condicionassem o futuro das nações. Acemoglu, Johnson e Robinson (2001, 2002), finalmente, utilizaram a moderna econometria e foram bem-sucedidos ao apresentar a tese para um público acadêmico bem mais amplo que os historiadores econômicos.

Argumentou-se também que o sucesso da tese em questão para públicos tão diversos decorre da sua plasticidade. Enquanto uns atribuem o atraso das ex-colônias de exploração à falta de instituições de mercado, outros focam na espoliação por uma elite interna ou externa. É importante notar que essa plasticidade da tese em relação às posturas ideológicas não depõe, obviamente, a favor de - nem contra - sua validade. Essa é uma questão empírica, e não da história das ideias. Discutir se de fato o futuro do Novo Mundo foi definido pelo tipo de colonização, e qual foi o mecanismo preciso, foge muito do alcance deste trabalho. 


\section{Referências}

ACEMOGLU, D.; JOHNSON, S.; ROBINSON, J. Reversal of fortune: geography and institutions in the making of the modern world income distribution. The Quarterly Journal of Economics, v. 117, n. 4, p. 1231-1294, Jan. 2002.

. The colonial origins of comparative development: an empirical investigation. The American Economic Review, v. 91, n. 5, p. 1369-1401, Dec. 2001. Disponível em: <https:// www.jstor.org/stable/2677930?seq=1\#page_scan_tab_contents > . Acesso em: 01 mar. 2015.

AGUILAR FILHO, H. A.; FONSECA, P. C. D. Instituições e cooperação social em Douglass North e nos intérpretes weberianos do atraso brasileiro. Estudos Econômicos, São Paulo, v. 41, n. 3, p. 551-571, set. 2011.

ALBOUY, D. Y. The colonial origins of comparative development: an empirical investigation: comment. The American Economic Review, v. 102, n. 6, p. 3059-3076, Oct. 2012.

BALDWIN, R. E. Patterns of development in newly settled regions. The Manchester School, v. 24, n. 2, p. 161-179, May 1956. Disponível em: < https://onlinelibrary.wiley.com/doi/ pdf/10.1111/j.1467-9957.1956.tb00981.x>. Acesso em: 01 mar. 2015.

BOIANOVSKY, M. 2017 HES Presidential Address: economists and their travels, or the time when JFK sent Douglass North on a mission to Brazil. Journal of the History of Economic Thought, v. 40, p. 149-177, 2018. $866,2009$.

. Furtado, North and the new economic history. Revista EconomiA, v. 10, n. 4, p. 849-

BOIANOVSKY, M.; MONASTERIO, L. O encontro entre Douglass North e Celso Furtado em 1961: visões alternativas sobre a economia nordestina. Revista Brasileira de Economia, Rio de Janeiro, v. 72, p. 275-291, 2018.

CAMERON, R. E. A concise economic history of the world: from paleolithic times to the present. Oxford: Oxford University Press, 1993.

CARDOSO, F. H.; FALETTO, E. Dependency and development in Latin America. Oakland: University of California Press, 1979.

CARVALHO FILHO, I.; MONASTERIO, L. Immigration and the origins of regional inequality: government-sponsored European migration to southern Brazil before World War I. Regional Science and Urban Economics, v. 42, n. 5, p. 794-807, set. 2012.

DÍAZ-ALEJANDRO, C. Latin America in the 1930s. In: THORP, R. (Ed.). Latin America in the 1930s: the role of the periphery in world crisis. New York: St. Martin's Press, 1984. v. 2. p. 17-49.

DOMAR, E. D. The causes of slavery or serfdom: a hypothesis. The Journal of Economic History, v. 30, n. 1, p. 18-32, Mar. 1970.

ENGERMAN, S.; SOKOLOFF, K. Factor endowments, institutions, and differential paths of growth among new world economies: a view from economic historians of the United States. 
In: HABER, S. How Latin America fell behind. Stanford, CA, US: Stanford University Press, 1997. p. 260-306.

FARR, J. Social capital a conceptual history. Political Theory, v. 32, n. 1, p. 6-33, Feb. 2004. Disponível em: <https://journals.sagepub.com/doi/abs/10.1177/0090591703254978>. Acesso em: 01 mar. 2015.

FERNANDES, M. Formação econômica do Brasil. São Paulo: Elsevier, 2011.

FOGEL, R.; ENGERMAN, S. Time on the cross. Boston: Little, Brown E Co., 1974.

FONSECA, E. G. Reflexões sobre a historiografia do pensamento econômico. Estudos Econômicos, São Paulo, v. 26, n. 2, p. 235-259, 1996.

FREYRE, G. Casa-grande $\mathcal{3}$ senzala: formação da família brasileira sob o regime de economia patriarcal. Rio de Janeiro: José Olympio, 1933.

FUNARI, P. P. P. Institutions, inequality, and long-term development: a perspective from Brazilian regions. Dissertação (Mestrado em Ciências) - Universidade de São Paulo, São Paulo, 2013. Disponível em: <http://www.teses.usp.br/teses/disponiveis/12/12138/tde29092014-175025/publico/PedroPauloPereiraFunari.pdf>. Acesso em: 01 mar. 2015.

FURTADO, C. Formação econômica do Brasil. São Paulo: Cia. Editora Nacional, 1959.

HEEREN, A. H. L. Handbuch der geschichte des europäischen staatensystems und seiner kolonien: von der entdeckung beyder indien bis zur errichtung des französichen kaiserthrons. Gottingen: M. Lechner, 1817.

HOBSON, J. A. Imperialism: a study. London: J. Nisbet, 1902.

LANDES, D. S. Why are we so rich and they so poor? The American Economic Review, v. 80, n. 2, p. 1-13, May 1990. Disponível em: <https:/www.jstor.org/stable/2006534?seq=1\#page_ scan_tab_contents>. Acesso em: 01 mar. 2015.

LEONIDIO, A. Em torno das origens: Leroy-Beaulieu e o pensamento social brasileiro. Estudos Sociedade e Agricultura, Rio de Janeiro, n. 13, p. 119-138, out. 1999. Disponível em: $<$ https://revistaesa.com/ojs/index.php/esa/article/view/163/159>. Acesso em: 01 mar. 2015.

LEROY-BEAULIEU, P. P. De la colonisation chez les peuples modernes. Paris: Guillaumin, 1902.

MANN, C. C. 1493: uncovering the new world Columbus created. New York: Alfred Knopf, 2013.

MARX, K. O capital: crítica da economia política. Rio de Janeiro: Civilização Brasileira, 2006.

MENEZES FILHO, N. et al. Instituições e diferenças de renda entre os estados brasileiros: uma análise histórica. In: ENCONTRO NACIONAL DE ECONOMIA, 34., 2006, Salvador. Anais... Salvador: Anpec, 2006. Disponível em: <http://www.anpec.org.br/encontro2006/ artigos/A06A070.pdf>. Acesso em: 01 mar. 2015.

MENGER, C. Gesammelte werke: grundsätze der volkswirtschaftslehre. Tübingen: Mohr Siebeck, 1968. 
NARITOMI, J.; SOARES, R. R.; ASSUNÇÃO, J. J. Institutional development and colonial heritage within Brazil. The Journal of Economic History, v. 72, n. 2, p. 393-422, 2012.

NORTH, D. C. Agriculture in regional economic growth. Journal of Farm Economics, v. 41, n. 5 , p. 943-951, Dec. 1959. Disponível em: <https:/www.jstor.org/stable/1235230?seq=1\#page_ scan_tab_contents $>$. Acesso em: 01 mar. 2015.

. Exports and regional economic growth: a reply. Journal of Political Economy, v. 64, n. 2, p. 165-168, 1956.

. Institutions, institutional change and economic performance. Cambridge: Cambridge University Press, 1990.

Location theory and regional economic growth. The Journal of Political Economy, v. 63, n. 3, p. 243-258, June 1955. Disponível em: < https://www.jstor.org/ stable/1825076?seq=1\#page_scan_tab_contents $>$. Acesso em: 01 mar. 2015.

. New economic history. Cambridge: Cambridge University Press, 1973.

. The economic growth of the United States 1790-1860. Englewood Cliffs, NJ, US: Prentice-Hall, 1961. Disponível em: <https://archive.org/details/economicgrowthofoonort>. Acesso em: 01 mar. 2015.

NOVAIS, F. A. Colonização e sistema colonial: discussão de conceitos e perspectiva histórica. SIMPÓSIO NACIONAL DOS PROFESSORES UNIVERSITÁRIOS DE HISTÓRIA, 4., 1969, Porto Alegre. Anais... São Paulo: USP, 1969. Disponível em: <https://pt.scribd.com/ document/131848994/NOVAIS-Colonizacao-e-Sistema-Colonial-ANPUH-1967>. Acesso em: 01 mar. 2015. 1986.

. Portugal e Brasil na crise do antigo sistema colonial (1777-1808). São Paulo: Hucitec,

PIERRE PAUL LEROY-BEAULIEU. In: CHISHOLM, H. The Encyclopedia Britannica: a dictionary of arts, sciences, literature and general information. London: Encyclopaedia Britannica Company, 1911. p. 485.

PRADO JÚNIOR, C. Formação do Brasil contemporâneo. São Paulo: Brasiliense, 1942. v. 1.

. História econômica do Brasil. São Paulo: Brasiliense, 1959. v. 9.

ROCHA, R.; FERRAZ, C.; SOARES, R. Human capital persistence and development. American Economic Journal: Applied Economics, v. 9, n. 4, p. 105-36, 2017.

ROSCHER, W. G. F. Kolonien, kolonialpolitik und auswanderung. Leipzig: Leipzig CF Winter, 1856.

SCHUMPETER, J. A. History of economic analysis. New York: Routledge, 1954.

SILVA NETO, J. M. A retórica da colonização nos liuros didáticos de história. 2012. 83 f. Dissertação (Mestrado em Educação) - Universidade Estácio de Sá, Rio de Janeiro, 2012. Disponível em: <http://portal.estacio.br/media/3377/silva_neto_jo\%C3\%A3o_marques_da_ disserta\%C3\%A7\%C3\%A30_21_05_2012_unesa.pdf>. Acesso em: 01 mar. $20 \overline{1} 5$. 
SMITH, A. An inquiry into the nature and causes of the wealth of the nations. Oxford: Oxford University Press, 1776.

VILLELA, A. O desenvolvimento econômico no Brasil pré-1945. In: VELOSO, F. et al. (Org.). Desenvolvimento econômico: uma perspectiva brasileira. Rio de Janeiro: Elsevier, 2013. p. 62-128.

VON THÜNEN, J. H. Der isolierte staat in beziehung auf landwirtschaft und nationalökonomie. Hamburg: Perthes, 1826.

WAKEFIELD, E. G. England and America: a comparison of the social and political state of both nations. London: R. Bentley, 1833.

WALLERSTEIN, I. The modern world-system I: capitalist agriculture and the origins of the European world-economy in the sixteenth century, with a new prologue. San Francisco: University of California Press, 2011.

Recebido em: 16/02/2017. Aceito em: 08/05/2017. 